\title{
JURISDIÇÃO CONSTITUCIONAL NO BRASIL: Uma Análise Crítica da Dicotomia Substancialismo vs. Procedimentalismo
}

http://dx.doi.org/10.21527/2176-6622.2021.56.8981

Recebido em: 24/4/2019

Modificações solicitadas em: 28/4/2021

Aceito em: 11/5/2021

Thiago Rafael Burckhart

Doutorando em "Diritto Comparato e Processi di Integrazione", Università degli Studi della Campania Luigi Vanvitelli, Dipartamento di Scienze Politiche Jean Monnet. Viale Ellittico - Caserta. 88110 - Itália. http://lattes.cnpq.br/9528776774218197. https://orcid.org/0000-0001-5483-9336. thiago.burckhart@gmail.com

\section{RESUMO}

A Constituição Federal de 1988 consolidou um modelo misto e complexo de jurisdição constitucional no Brasil. Ao longo de seus 30 anos de vigência, a preocupação com a efetividade de seus dispositivos implicou a importação de teorias para legitimar ou não as práticas de magistrados neste âmbito. A discussão sobre a dicotomia "substancialismo" vs. "procedimentalismo" se posiciona nesta interface. 0 objetivo deste trabalho é de fornecer subsídios teóricos para uma análise crítica sobre a transposição deste debate ao cenário jurídico-constitucional brasileiro, buscando verificar em que medida ele se harmoniza com o modelo de controle de constitucionalidade insculpido pela Constituição de 1988. A hipótese a ser averiguada é de que a importação destas teorias, mediante transplantes jurídicos na ordem do formante doutrinário, construídas em uma família jurídica distinta daquela brasileira - qual seja, aquela da common law - exige um grau de adequação ao sistema constitucional nacional, como é o caso brasileiro. O trabalho insere-se no campo da Teoria Constitucional, com aportes da dogmática constitucional, comparação constitucional e da teoria política, sendo realizado mediante o método hipotético-dedutivo.

Palavas-chave: Jurisdição constitucional; Brasil; substancialismo; procedimentalismo; análise crítica.

\section{CONSTITUTIONAL JUSTICE IN BRASIL: A CRITICAL REVIEW ON THE SUBSTANTIALISM AND PROCEDURALISM DICHOTOMY}

\section{ABSTRACT}

The Federal Constitution of 1988 has consolidated a mixed and complex model of constitutional jurisdiction in Brazil. Throughout its 30 years of existence, the concern with the effectiveness of its devices implied on the importation of different theories to legitimize or not the practices of judges in this area. The discussion about "substantialism" vs. "Proceduralism" is positioned on this interface. Taking it in consideration, the aim of this paper is to furnish theoretical subsides for a critical analyze of this debate transposition to the Brazilian legal-constitutional scenario, seeking to verify to what extent it harmonizes with the Brazilian judicial review model provided by the 1988 Constitution. The hypothesis states to affirm that the importation of these theories, through legal transplants by the doctrinal formant, built in a distinct legal family from that of Brazil - that is, that of common law - requires a certain adaptation to the national constitutional system. The article is inserted in the field of Constitutional Theory, with contributions of constitutional dogmatics, constitutional comparison and political theory, and is carried out through the hypothetical-deductive method.

Keywords: Constitutional jurisdiction; Brazil; substantialism; procedimentalism; critical analysis. 


\section{INTRODUÇÃO}

Desde a promulgação da Constituição de 1988 e o aprimoramento de um modelo "misto" de controle de constitucionalidade, a jurisdição tornou-se um tema de grande envergadura nos estudos constitucionais. Em efeito, trata-se de um fenômeno que encontra correspondência em outras democracias constitucionais em todo o mundo, que, desde o final da Segunda Guerra Mundial, vem introduzindo e aprimorando seus sistemas de justiça constitucional. No Brasil, este processo é impulsionado por diferentes causas, dentre elas a violação sistemática de direitos fundamentais, a perda de legitimidade das instituições políticas representativas e o processo de judicialização da política, que projetam no Judiciário e, sobretudo, no Supremo Tribunal Federal, a confiança para com a tutela de direitos.

Nesse contexto, a preocupação com a atuação do Judiciário no âmbito da jurisdição constitucional, a qualidade das decisões e sua legitimidade jurídica, abriu o caminho para a introjeção de literaturas jurídicas estrangeiras com o intuito de interpretar os novos fenômenos jurídicos no país. A discussão relativa à dicotomia "procedimentalistas" vs. "substancialistas" se posiciona nesta interface. Estas são duas perspectivas tratadas como antagônicas por grande parte da literatura jurídico-constitucional anglo-saxã e brasileira. Em síntese, os substancialistas, representados em grande medida pela obra do estadunidense Ronald Dworkin, defendem que o Judiciário é o lócus por excelência da democracia, tendo o juiz uma tarefa primordial na defesa dos direitos fundamentais, na medida em que ele é considerado um sujeito apolítico, por encontrar-se "fora" do jogo político e, por isso, ser mais adequado que ele decida - e reconheça - sobre os direitos fundamentais a partir da interlocução com os princípios constitucionais. Por outro lado, os procedimentalistas, retratados sobretudo pela obra do estadunidense John Hart Ely, entendem que o judicial review deve ser realizado de forma racionalizada, somente em casos pontuais, de modo que os poderes representativos são, por excelência, o lócus privilegiado da democracia.

Nesse sentido, o objetivo deste artigo é de fornecer subsídios teóricos para uma análise crítica sobre a transposição deste debate ao cenário jurídico-constitucional brasileiro, buscando verificar em que medida ele se harmoniza com o modelo de controle de constitucionalidade insculpido pela Constituição de 1988. A hipótese a ser averiguada é de que a importação destas teorias, mediante transplantes jurídicos na ordem do formante doutrinário, construídas em uma família jurídica distinta daquela brasileira - qual seja, aquela da common law - exige um grau de adequação ao sistema constitucional nacional, como é o caso brasileiro. 0 trabalho insere-se no campo da Teoria Constitucional, com aportes da dogmática constitucional, comparação constitucional e da teoria política, sendo realizado mediante o método hipotético-dedutivo, e divide-se em quatro partes além desta Introdução: 2) Jurisdição constitucional no Brasil: um modelo complexo; 3) As teses procedimentalistas; 4) As teses substancialistas; 5) Uma análise crítica; contém, também, para finalizar, as considerações finais e referências bibliográficas consultadas.

\section{JURISDIÇÃO CONSTITUCIONAL NO BRASIL: UM MODELO COMPLEXO}

Logo após a Segunda Guerra Mundial nota-se que houve um redesenho do constitucionalismo em âmbito planetário. Nesse sentido, Bruce Ackerman aponta para o "advento do constitucionalismo global" (ACKERMAN, 1997; ONIDA, 2008), na medida em que esse fenômeno deixa de ser um ideário da política ocidental territorializado - relativo às Américas e à Europa - e passa a se tornar um ideal tendencialmente universal $^{1}$. Da mesma forma, a democracia também passou a se firmar como um ideário político global, deixando de ser uma concepção ideal tratada por muitos teóricos de modo pejorativo para se alçar como modelo de regime político dominante (SANTOS; AVRITZER, 2002; MIGUEL, 2014). A intersecção entre o constitucionalismo e a democracia - especialmente em razão da constitucionalização da democracia nos textos constitucionais de diversos países, inclusive no Brasil - resultou na construção da categoria "democracias constitucionais" - ou também "Estado democrático de direito" - que passou a ser integrada ao discurso jurídico e político.

\footnotetext{
Nesse sentido, “(...) la seconda guerra mondiale costituisce un tornante storico fondamentale. Essa infatti segna l'affermazione a livello planetario dei principi del costituzionalismo come principi non propri di questo o quel popolo o di questa o quella area geopolitica, ma tendenzialmente universali" (ONIDA, 2008, p. 3-4). Para aprofundamentos, ver também Tushnet (2009).
} 
O constitucionalismo contemporâneo ${ }^{2}$, que se desenvolveu paulatinamente desde então, como resultado de uma série de incursões teorético-filosóficas, alterou diretamente o direito, como afirma Manuel Atienza (2003). As alterações se deram em duas vias. A primeira a partir de uma aproximação do direito com "novos conteúdos" que, anteriormente, estavam adstritos ao campo da reflexão ético-filosófica e política; e, num segundo momento, por um processo de constitucionalização do direito, na medida em que inúmeros direitos, que até então estavam relegados a serem reconhecidos pelo processo legislativo, passaram a integrar a Constituição e a ser, portanto, uma forma de limitar a política ordinária.

Essa constatação também é feita pelo professor francês Louis Favoreu (2001), o qual aponta que o fenômeno da "constitucionalização" produziu uma mudança no centro de gravidade da ordem jurídica. $O$ autor ressalta que "desde el siglo XIX, ese orden tuvo a la ley como eje esencial. A partir de fines del siglo XX, el eje es la Carta Fundamental" (FAVOREU, 2001). A Constituição deixa de ser um mero documento político ou preambular e passa a ter força jurídica e normativa, posicionando-se, ainda, na centralidade do sistema jurídico, como já era nos Estados Unidos da América desde o século 18. Passa-se, assim, para um contexto no qual o modelo de soberania parlamentar, vigente em grande parte da Europa do século 17 à metade do século 20, passa a ter de dialogar com a concepção insurgente de "soberania constitucional" (ZAGREBELSKY, 2003), na qual a Constituição, documento que inscreve restrições aos poderes políticos, ganha prevalência.

Essa transformação produziu efeitos no âmbito da relação entre poderes, à medida que um Poder passou a assumir destaque no cenário jurídico e político: o Judiciário. De mero poder responsável por ser "la bouche de la loi", como afirmava Montesquieu no século 18 - e como efetivamente o fora até metade do século 20 -, o Judiciário passou a assumir um novo papel desde aquele momento. Isso ocorre, sobretudo, em razão do nascimento de Tribunais Constitucionais na Europa, América Latina e em parte do mundo oriental, responsáveis pela interpretação e aplicação da Constituição ${ }^{3}$.

Enquanto o constitucionalismo, entendido como movimento histórico, político, cultural e jurídico ${ }^{4}$, tem uma longa história, o jurista alemão Dieter Grimm (2001) afirma que a jurisdição constitucional e as cortes constitucionais eram raridade antes do final da Segunda Guerra Mundial. A essência da jurisdição constitucional, como trata Dieter Grimm (2001), "is to enforce constitutional law vis-à-vis government" (p. 125), o que implica a afirmação do recurso do controle de constitucionalidade - chamado pela literatura inglesa de judicial review - de leis e atos administrativos realizados pelo Legislativo e Executivo, tendo em vista os parâmetros e limites normativos estabelecidos pela Constituição, que funcionam, ao menos teoricamente, como freios aos poderes políticos.

O processo de constitucionalização dos direitos, o princípio da constitucionalidade das leis e a transformação da Constituição em "norma jurídica" implicam, como diria o jurista austríaco Hans Kelsen, no estabelecimento de Tribunais Constitucionais capazes de realizar o controle de constitucionalidade de leis e atos administrativos, além de estabelecer a interpretação em última instância dos dispositivos da Constituição. 0 modelo, idealizado por Hans Kelsen em seu clássico livro "Jurisdição Constitucional" $(2003)^{5}$, compreende um controle abstrato de normas, realizado unicamente pelos Tribunais Constitucionais de modo concentrado. Os magistrados da corte podem, em seu modelo, atuar como "legisladores negativos", na medida em que as leis infrinjam requisitos constitucionais.

Para Hans Kelsen, o "guardião" da Constituição deve ser um Tribunal de Justiça Constitucional, e por isso arquitetou um modelo de Tribunal Constitucional responsável pela revisão de atos dos poderes políticos. O modelo idealizado por Kelsen passou a ser aplicado de modo difuso nos países europeus continentais logo após a Segunda Guerra Mundial. Este modelo contrapõe-se ao desenvolvido nos Estados Unidos da América

\footnotetext{
O termo "constitucionalismo contemporâneo" é também utilizado para caracterizar uma nova fase do constitucionalismo moderno, logo após o constitucionalismo liberal dos séculos 18 e 19 e o constitucionalismo social do século 20, no qual passa a aproximar-se do ideal democrático, naquilo que ficou conhecido como "direitos de terceira geração" (BOBBIO; MATTEUCCI; PASQUINO, 1998; FERRAJOLLI, 2012a).

3 Para aprofundamentos, ver Hirschl (2007).

${ }_{4}$ Neste trabalho compreende-se que o constitucionalismo moderno resulta da articulação sinérgica diante da necessidade de a) declarar direitos fundamentais; b) estabelecer a organização estatal, ambas como formas de limitação à política; e c) na sua forma escrita. Cfe. Canotilho (1993).

${ }^{5}$ Cabe aqui mencionar, ainda, o debate Hans Kelsen vs. Carl Schmitt, que marcou a teoria do direito no século 20 (SCHMITT, 2007).
} 
a partir do famoso caso Marbury vs. Madison, julgado pela Corte Suprema no início do século 19. No caso estadunidense, o controle de constitucionalidade não foi idealizado por determinado autor, mas se desenvolveu a partir da própria jurisprudência da Corte Suprema. Nesse contexto, a decisão do caso Marbury vs. Madison teve um papel fundamental no desenho do controle de constitucionalidade estadunidense, que floresceu a partir de pressupostos diferentes do sistema europeu, na medida em que é um sistema de ordem "concreta", realizado de forma difusa por todos os juízes estadunidenses ${ }^{6}$.

No Brasil, o controle de constitucionalidade foi primeiramente recepcionado pela ordem constitucional de 1891, primeira Constituição republicana ${ }^{7}$. O modelo adotado foi o estadunidense, marcado pelo controle concreto e difuso, permanecendo vigente até 1965, quando, mediante uma emenda à Constituição de 1946, foi acrescentado o modelo abstrato e concentrado de constitucionalidade, que passou a ser incrementado pela Constituição de $1988^{8}$. O Brasil, portanto, convive, em seu ordenamento jurídico, com ambos os sistemas de controle de constitucionalidade, sendo um modelo peculiar e altamente complexo ${ }^{9}$. A Constituição de 1988 foi responsável pela recepção deste modelo "misto" de controle judicial de constitucionalidade, além de ter sido - do ponto de vista teórico-epistemológico - o documento que recepcionou as transformações do direito constitucional no âmbito do constitucionalismo contemporâneo.

O modelo misto brasileiro ainda passou por mudanças e incrementos desde a promulgação do texto constitucional. No que se refere ao controle de constitucionalidade, as mudanças substanciais foram realizadas pela Emenda Constitucional n. 3/2003, que a) criou a Ação Declaratória de Constitucionalidade de lei ou ato normativo federal; b) criou a Ação de Descumprimento de Preceito Fundamental; c) atribuiu eficácia erga omnes e efeito vinculante às decisões definitivas de mérito proferidas pelo STF em sede de Ação Declaratória de Constitucionalidade de lei ou ato normativo federal ${ }^{10}$. Além disso, em âmbito infraconstitucional, houve a aprovação da Lei n. 9.868/99 e da Lei n. 9.882/99, que regulamentam o julgamento e processamento da ADI, ADC e ADPF perante o STF. Já a Emenda Constitucional n. 45/2004 foi responsável por designar novos mecanismos no sistema de controle concreto de constitucionalidade, acompanhada pela Emenda Regimental do STF n. 45, de 2011, que amplificou as competências das turmas do STF para o processo e julgamento de inúmeras classes processuais (MEDEIROS, 2013, p. 206).

Pode-se afirmar, nesse contexto, que o modelo de controle judicial de constitucionalidade brasileiro é marcado por uma alta complexidade por diversos fatores: a) pelo fato de admitir a confluência de dois modelos diferentes; b) pelo fato de o STF não ser essencialmente uma "Corte Constitucional" em stricto sensu, mas também funcionar como última instância do Judiciário; c) pelo fato de haver escassa deliberação nas instâncias Judiciais no controle de constitucionalidade, com alto número de decisões monocráticas; e d) pelo fato de que inexistem parâmetros claros sobre a atuação do STF e do Judiciário de modo geral no controle de constitucionalidade, sobretudo nas causas em que a Constituição garante a este Poder uma atuação mais "política" que "jurídica". É em razão disso que o modelo judicial de controle de constitucionalidade brasileiro pode ser considerado "complexo".

A complexidade deste modelo e a preocupação com a atuação do Judiciário neste âmbito, em especial com a qualidade das decisões e sua legitimidade jurídica e política, impulsionou a introjeção de literaturas jurídicas estrangeiras no âmago da reflexão jurídico-constitucional brasileira, notadamente daquela de matriz anglo-saxã de common law - como é o caso da literatura constitucional estadunidense - com o intuito de fornecer subsídios teóricos para interpretar esses fenômenos no Brasil. A discussão entre "procedimentalistas" e "substancialistas", importada da realidade constitucional estadunidense para o contexto brasileiro, posiciona-se nesta interface.

\footnotetext{
${ }_{6}$ Para compreender o caso Marbury vs. Madinson e suas implicações para o Judicial Review, ver Corwin (1914).

7 Sua inserção no ordenamento jurídico brasileiro não foi realizada pelo texto constitucional, mas por meio do Decreto n. 848 de 1890 , que fora recepcionado pela Constituição de 1891, no qual passou a prever o instituto no texto constitucional.

8 Para uma análise da história do controle de constitucionalidade no Brasil, ver Arantes (1997).

9 Cabe ressaltar que o sistema jurídico brasileiro ainda comporta, para além do controle judicial de constitucionalidade, o controle político de constitucionalidade realizado pelo Poder Legislativo no âmbito do processo legislativo na Câmara dos Deputados e no Senado Federal.

${ }^{10}$ Ressalta-se que as iniciativas para a reforma do Judiciário não partiram somente do Poder Legislativo. O Poder Executivo criou a Secretaria de Reforma do Judiciário, ligada ao Ministério da Justiça.
} 


\section{AS TESES PROCEDIMENTALISTAS}

John Hart Ely, teórico estadunidense da segunda metade do século 20, inicia sua obra mais conhecida, intitulada "Democracia e desconfiança: uma teoria do controle judicial de constitucionalidade" (2016), afirmando que o debate constitucional estadunidense das décadas de 70 e 80 do século 20 estava dominado por uma falsa dicotomia. De um lado encontram-se os não interpretacionistas, ou positivistas exegéticos, que advogam no sentido de que a interpretação constitucional deve se ater ao pensamento e às intenções daqueles que escreveram o texto constitucional, de modo que o controle de constitucionalidade deve ser limitado à defesa daquilo que está explicitamente estabelecido no texto e na intenção do constituinte originário sem grande espaço para a interpretação a partir de elementos externos ao direito. Do outro lado encontram-se os interpretacionistas, ou jusnaturalistas, que defendem a necessidade de buscar elementos extrínsecos à Constituição - valores e princípios morais - para legitimar a interpretação constitucional e gerar um bom funcionamento do controle de constitucionalidade na medida em que este último reavaliaria as opções valorativas do legislativo ${ }^{11}$.

De acordo com o autor, "cada um desses lados está interessado em sustentar a ideia de que essas são as únicas opções possíveis" (ELY, 2016, p. 3), como se não houvesse qualquer possibilidade de superá-las. Nesse sentido, Ely é categórico ao afirmar que "nenhuma das teorias professadas [...] é, em última análise, compatível com os pressupostos democráticos implícitos em nosso sistema" (ELY, 2016, p. 3). Ely constata, entretanto, que nenhuma das referidas teorias está concernida com a via democrática. A abordagem interpretacionista, por diversos motivos, é incapaz de manter-se fiel ao espírito de certas disposições constitucionais, o que dificulta sua aplicabilidade prática e ainda aumenta a tensão existente entre constitucionalismo e democracia (ELY, 2016, p. 97). Já a abordagem não interpretacionista é falha no sentido de tentar fundamentar o direito e a interpretação jurídica em fenômenos extrínsecos ao próprio direito ${ }^{12}$. Nesse sentido, a interpretação constitucional estaria inscrita no risco corrente de imposição, por parte dos juízes, de seus próprios valores e de sua própria moral, uma vez que os magistrados, "em vários contextos jurídicos, tinham uma predisposição, consciente ou não, de inserir seus valores pessoais em seus argumentos jurídicos" (ELY, 2016, p. 58) ${ }^{13}$, o que resultaria em uma imposição paternalista, seja quando se recorre a valores próprios do juiz, ao direito natural, aos princípios neutros, à razão, à tradição, ao consenso ou à previsão do progresso do projeto constitucional ${ }^{14}$.

Tomando isso em consideração, Ely busca construir, em seu livro, uma espécie de "terceira via" ao problema exposto, tentando conciliar a necessidade do controle de constitucionalidade com base em pressupostos da democracia representativa. Nesse sentido, o autor vai recorrer a uma famosa nota de rodapé da Suprema Corte dos Estados Unidos, inscrita no caso United States vs. Carolene Products Co., julgado em 1938. Neste caso, em que se discutiu a constitucionalidade de uma lei que proibia o transporte interestadual de leite com óleo vegetal, a Suprema Corte estadunidense estabeleceu, em sua nota de rodapé número 4, três pressupostos que fundamentariam a atuação da corte - "modo de agir da Corte", como apregoa Ely (2016, p. 100), em sede de controle judicial de constitucionalidade.

A presunção de constitucionalidade pode ter margem mais estreita quando a legislação parece, à primeira vista, estar compreendida numa proibição específica da Constituição, tal como as das dez primeiras emendas, consideradas igualmente específicas quando entendidas como contidas na Décima quarta emenda [...]. Não será necessário, agora, considerar se uma lei que restringe aqueles processos políticos dos quais, via de regra, pode-se esperar que provoquem a revogação das leis indesejáveis, deverá estar sujeita a uma análise judicial

\footnotetext{
${ }_{11}$ De acordo com Paul Cox (1981): "Ely describes competing theories as falling within one or the other of two general positions regarding the question of appropriate judicial reference point: the interpretivist' and noninterpretivist (or fundamental value) 8 positions. Both, in Ely's view, are inadequate. Interpretivism limits judicial discretion by insisting that constitutional text has discoverable meaning and that judicial decision is legitimate only to the extent that it is traceable to that meaning" (p. 638).

12 "Uma abordagem intepretacionista - pelo menos uma abordagem intepretacionista que aborde as disposições da Constituição como unidades contidas em si mesmas - mostra-se, quando submetida à análise, incapaz de manter-se fiel ao espírito evidente de certas disposições. Entretanto, quando buscamos uma fonte externa de valores para preencher a textura aberta da Constituição - uma fonte que não transforme a Corte num simples conselho de controle legislativo - nada encontramos" (ELY, 2016. p. 97.

13 "Ely proposes a new approach to judicial review, determining that dilema undermining constitutional interpretation are methods left ambiguous to judge, such as the incorporation if their personal values" (HUNTER, 2005, p. 92).

14 Para uma análise mais exaustiva, ver Poli (2012, p. 86-87).
} 
mais rigorosa (no que a maioria dos outros tipos de legislação [...]. Também não será necessário procurar saber se considerações do mesmo naipe devem influenciar o controle de leis direcionadas a certas minorias religiosas (...) ou de nacionalidade (...) ou raciais (...); se o preconceito contra minorias separadas e isoladas (descrete and insular minorities) pode ser uma condição especial que tende a restringir seriamente o funcionamento dos processos políticos em que costumamos nos basear para proteger as minorias, e que pode exigir, nessa mesma medida, um exame judicial mais minucioso (ELY, 2016, p. 100-101).

Disto depreende-se que é dever da Suprema Corte no controle de constitucionalidade: 1) proteger a Constituição; 2) intervir no processo político, como uma espécie de árbitro político, para proteger o bom funcionamento do sistema democrático; 3) analisar a forma como as minorias insulares são tratadas pelas maiorias no processo democrático-representativo. Referida decisão foi proferida pela Corte estadunidense sob a égide da Era Warren, momento marcado por um ativismo de cunho progressista. Ely (2006) afirma, entretanto, que este ativismo foi edificado não no sentido de seus membros intentarem impor valores substantivos constitucionais em suas decisões, mas marcado pelo desejo de "assegurar que o processo político [...] estivesse aberto aos adeptos de todos os pontos de vista, em condições de relativa igualdade" (ELY, 2016, p. 98), o que a diferencia da também ativista corte de Warren (ELY, 2016, p. 99), de cunho conservador. Nesse sentido, Ely (2006) buscou construir uma teoria do controle de constitucionalidade que tenha por base o favorecimento da representatividade política no âmago do processo político e que fosse orientada para a participação política da maior possibilidade de pessoas possíveis (POLI, 2012, p. 89).

Nessa esteira, Ely constrói, em seu livro, a abordagem da corte constitucional como "árbitro do mercado político", na qual ela atua no controle do processo de representação ${ }^{15}$. Para ele, a desobstrução dos canais de mudança política e a correção de certos tipos de discriminação contra as minorias, "se combinam para formar uma teoria coerente do governo representativo, ou se, como às vezes se afirma, eles são na verdade impulsos incompatíveis entre si" (ELY, 2016, p. 99). Esse tipo de abordagem posiciona a corte como uma espécie de árbitro do "mercado político", como assevera Ely, na medida em que ela opera quando há desconfiança para com o sistema político, ou seja, quando há um mal funcionamento dele (ELY, 2016, p. 99). De acordo com Ely (2016):

Numa democracia representativa, as determinações de valor devem ser feitas pelos representantes eleitos; e, se a maioria parlamentar desaprová-los, poderá destituí-los através do voto. 0 mal funcionamento ocorre quando o processo não merece nossa confiança, quando (1) os incluídos estão obstruindo os canais de mudança política para assegurar que continuem sendo incluídos e os excluídos permaneçam onde estão, ou (2) quando, embora a ninguém se neguem explicitamente a voz e o voto, os representantes ligados à maioria efetiva sistematicamente põem em desvantagem alguma minoria, devido à mera hostilidade ou à recusa preconceituosa em reconhecer uma comunhão de interesses - e, portanto, negam a essa minoria a proteção que o sistema representativo fornece a outros grupos (p. 137).

As determinações de valor, portanto, são uma tarefa que, para Ely, estão a cargo do Poder Legislativo e Executivo - os Poderes legitimamente eleitos. Não caberia a uma suprema corte - e ao Judiciário de modo geral - a imposição de valores supostamente constitucionais em sua análise e argumentação jurídica. Isso porque os magistrados "estão relativamente à margem do sistema governamental", e tal fato "[...] não lhes dá um canal de acesso especial aos valores genuínos do povo norte-americano: na verdade, pelo contrário, praticamente assegura que não terão esse acesso" (ELY, 2016, p. 137). Essa seria uma forma de buscar uma "abordagem satisfatória" para a decisão judicial, no entender de Ely ${ }^{16}$.

Essas seriam as bases para uma práxis do controle de constitucionalidade condizente com os pressupostos democráticos. Ely toma como pressuposto o fato de que a democracia representativa é uma realidade incontornável dos sistemas políticos contemporâneas, de modo que o controle de constitucionalidade com pressupostos democráticos deve ser sensível ao bom funcionamento deste sistema de representação. Trata-se de uma "preocupação processual num sentido mais amplo - com o procedimento por meio do qual são feitas

${ }_{15}$ Trata-se do que Ely veio a chamar de "representation-reinforcement judicial review", que "endeavors to open the political processes and purify them of prejudice without blocking democratic outcomes" (Cfe. BRUBACKER, 1982, p. 208).

${ }^{16}$ Para aprofundamentos, ver Grano (1981). 
as leis que governam a sociedade - que também permeia suas outras decisões" (ELY, 2016, p. 98) ${ }^{17}$. Ely é, nesse sentido, considerado um autor prodecimentalista, não por desmerecer a substancialidade dos valores constitucionais - haja vista que a Constituição dos Estados Unidos da América é essencialmente procedimental -, mas pelo fato de conceber que esses valores devem ser determinados pelos poderes legitimamente eleitos e não por aquele que não o é ${ }^{18}$. Nos dois últimos capítulos de seu livro, Ely desenvolve os dois argumentos que sustentam a sua teoria constitucional do controle constitucional, que posiciona a Suprema Corte como árbitro do jogo político: o desbloqueio dos canais de mudança política e a facilitação da representação de minorias ${ }^{19}$ que são tratados como pressupostos intrínsecos da prática do controle de constitucionalidade procedimental.

Seguindo a proposta teórica de Ely, outros autores também podem ser considerados "procedimentalistas" no que se refere à proposta do controle de constitucionalidade ${ }^{20}$, sendo, talvez, o mais expressivo, Jürgen Habermas (1997). Em certo sentido, pode-se afirmar que Habermas aprimora a teoria de Ely na medida em que desenvolve um modelo de controle de constitucionalidade com forte apelo ao modelo de democracia deliberativa - aspecto que não é trabalhado de forma contundente na obra de Ely, muito embora este último tenha aberto o caminho para tanto. Habermas argumenta, partindo de uma concepção ideal de democracia, que o processo de formação democrática da opinião e da vontade comum, "se traduz em eleições gerais e em decisões parlamentares" (1995, p. 36), de modo que a política deliberativa contribui para o desenvolvimento do agir comunicativo, que se manifesta a partir dos processos de entendimento mútuos e da tomada de posição do sujeito ante as questões sociais.

Dessa forma, Habermas partilha de uma visão que é competência do tribunal constitucional - a função de evitar a posição paternalista que compreende a imposição de valores -, de modo que "ao direito e à jurisdição constitucional, por consequência, competem os discursos de aplicação, não de justificação" (RADKE; TEIXEIRA, 2017, p. 100). Embora Habermas admita - tal como Ely - que os tribunais devem agir de forma contramajoritária, para a defesa dos direitos fundamentais e também na medida em que compete aos tribunais a proteção de minorias vítimas da omissão estatal (RADKE; TEIXEIRA, 2017, p. 101), ele não admite que os magistrados de um tribunal constitucional, ou mesmo de outras formas de jurisdição, usurpem o papel de ir além de sua tarefa, como uma prática de ativismo judicial. Na sua visão, essa prática estaria em descompasso com a democracia deliberativa, além de representar riscos para a separação de poderes.

A partir de um esforço de síntese, pode-se categorizar a "corrente procedimental" do controle de constitucionalidade em três características principais: 1) a conciliação dos ideais do constitucionalismo e da democracia no âmbito de uma tensão produtiva; 2) a aposta no modelo de democracia deliberativa; 3) um modelo de controle de constitucionalidade discreto que age para garantir a democracia, tutelar os direitos fundamentais e a participação das minorias nos debates políticos. É desse modo que se pode caracterizar o procedimentalismo enquanto corrente de pensamento sobre a jurisdição constitucional.

\footnotetext{
$\overline{17}$ Nas palavras de Ana Luiza Almeida Ferro (2010), "De tendência formalista, propugna uma forma de controle de constitucionalidade, justificada na própria natureza da Constituição dos Estados Unidos e no sistema americano de democracia representativa, orientada para questões de participação e não para os méritos substantivos da escolha política sob ataque" (p. 2). Nesse sentido, "Ely sees the constitution as a naked document, one that is part of the machinery of answers and a tool of government. The interpretation of the constitution should not incorporate the use of principles and values. Rather, Ely notes that interpretation should be part of the political process, with decision-making as part of the elected official political process, rather than that by an unelected judge. The value of elected officials, notes Ely, is their access to clear channels of political change. This relegates judges to a position of value where there is an issue concerning minorities" (HUNTER, 2005, p. 95).

${ }^{18}$ Aqui cabe mencionar a tensão existente entre o procedimentalismo e o substancialismo constitucional, que será mais bem analisada adiante. "Ely's attack upon 'fundamental values' simultaneously seeks to demonstrate both that substantive fundamental values are inherently subjective and that a reliance upon them is a prescription for unbridled judicial discretion hopelessly inconsistent with a commitment to representative democracy" (COX, 1981, p. 639).

19 “Da pretensão de aperfeiçoar a premissa majoritária, portanto, ao invés de abandoná-la, Ely deriva o papel que o poder judiciário poderia legitimamente exercer em um regime democrático. Como nota fundamental, o intervencionismo autorizado por esse tipo de controle só poderia tratar de questões estritamente vinculadas ao processo político, e nunca do conteúdo substantivo das decisões legislativas impugnadas, seja ela qual for" (POLI, 2012, p. 89).

${ }^{20}$ Nesse sentido, apesar das divergências teóricas, pode-se citar também a obra de Nino (1997).
} 


\section{AS TESES SUBSTANCIALISTAS}

As teorias do procedimentalismo democrático de Ely e Habermas são contrapostas aos teóricos categorizados como "substancialistas". Neste terreno, o trabalho do teórico e filósofo estadunidense Ronald Dworkin é considerado de grande valia para essa corrente de pensamento, de modo que sua teoria do controle de constitucionalidade edifica-se com pontos em tensão e contradição com a proposta propugnada pelos procedimentalistas. Ronald Dworkin edifica uma sólida e bem elaborada teoria do direito e da Constituição com base em uma teoria da justiça, apresentada em diversos livros: "Taking Rights Seriously" (1977a), "A Matter of Principle" (1985), "Law's empire" (1986) e "Freedom's law" (1977b). Partindo do modelo de direito da common law, Dworkin propõe uma teoria interpretativa do direito que se contrapõe ao Positivismo Jurídico de Herbert Hart (2000) e ao utilitarismo de Jeremy Bentham (2000). Para Dworkin, uma teoria do direito deve ser subjacente a uma teoria da legitimidade e a uma teoria da justiça legislativa, sendo esta, para ele, a "questão politicamente sensível do constitucionalismo".

Nesse sentido, como elemento constitutivo de sua teoria, Dworkin constrói um modelo de normas no qual os princípios não representam uma dimensão extrínseca ao discurso jurídico, mas constituem o campo normativo do que se compreende por direito. O autor realiza uma distinção técnica entre "regras" e "princípios" - distinção esta que é encarada pela teoria do direito brasileira hegemônica como elementos constitutivos da norma (DWORKIN, 1977a, p. 23-72). Nesse contexto, Dworkin constrói a tese da "comunidade de princípios", levando em consideração o fato de que "somos súditos do império do direito, vassalos de seus métodos e ideais, subjugados em espírito enquanto discutimos o que devemos portanto fazer" (1986, p. 137). Dworkin compreende que o direito, entendido enquanto regra e princípio, indubitavelmente cria uma possibilidade maior de argumentação, tendo em vista a elasticidade dos princípios presentes na Constituição e nos diferentes ramos do direito no âmbito das suas especificidades. Todos os que participam desse processo interpretativo ${ }^{21}$, sobretudo os atores do Poder Judiciário, são responsáveis pela intepretação da lei e fazem parte da referida "comunidade".

Para Dworkin, os juízes são obrigados a considerar os princípios na análise de casos adjudicados sob o risco de negação explícita do próprio conteúdo normativo do direito. Uma interpretação jurídica, contudo, com base em princípios, não significa o mesmo que a possibilidade de juízes imporem sua moral ou seus valores pessoais na prática interpretativa, isso porque uma interpretação com base em princípios é diferente da interpretação política. Os argumentos de princípios, na visão de Dworkin, são "baseados em direitos", na medida em que eles integram tecnicamente a própria estrutura daquilo que o autor considera ser o fenômeno jurídico. Já os argumentos políticos são externos ao direito, relativos, portanto, a uma outra racionalidade. Nesse contexto, "o julgamento é, caracteristicamente, uma questão antes de princípio que de política" (DWORKIN, 1985, p. X) sendo uma atividade estritamente jurídica.

A noção de "direito enquanto integridade", construída pelo autor, também posiciona Dworkin como contrário tanto ao passivismo ${ }^{22}$ - como entende Sunstein - quanto ao ativismo judicial. Ambas as perspectivas são equivocadas na perspectiva de Dworkin; o passivismo porque, em suma, implica que os indivíduos não têm direitos contra maiorias política, e o ativismo por ignorar o texto da Constituição, a história de sua pro-

\footnotetext{
${ }^{21}$ Para Dworkin, "a análise jurídica é fundamentalmente interpretativa, e oferece uma avaliação geral da interpretação para descrever em que sentido ela assim é" (DWORKIN, 1985, p. X).

22 "O passivismo parece, à primeira vista, uma teoria atraente sobre a medida em que os juízes devem impor sua vontade às maiorias políticas. Quando, porém, tomamos o cuidado de desemaranhar os diferentes problemas que mistura, seus fundamentos intelectuais tornam-se invariavelmente mais frágeis. Deve ser ou conter uma teoria sobre o que a Constituição já é enquanto direito fundamental, o que significa que deve ser uma interpretação da prática constitucional entendida em sentido amplo. O passivismo apenas precariamente se ajusta a essa prática, e só a mostra em sua melhor perspectiva se admitirmos que, como questão de justiça, os indivíduos não têm direitos contra as maiorias políticas - o que é estranho à nossa cultura constitucional - ou que a eqüidade, definida de um modo especial que zomba da própria ideia de direitos constitucionais, é a virtude constitucional mais importante. Se rejeitarmos essas ideias nada atraentes, rejeitaremos o passivismo. Isso significa que devemos aceitar a teoria contrária, a teoria bicho-papão que os passivistas chamam de 'ativismo'?" (DWORKIN, 1986. 451).
} 
mulgação, as decisões anteriores e as tradições da cultura jurídica ${ }^{23}$. O direito, enquanto integridade, é uma teoria que propõe uma prática que consiste numa premissa de direção do Estado, mais que uma pura prática interpretativa, pois vincula tanto a atuação do Legislativo quanto o Judiciário ${ }^{24}$ - apesar de Dworkin focalizar este último.

A integridade é, portanto, um ideal político que exige do Estado e da sociedade que ajam de acordo com um conjunto único e coerente de princípios, mesmo quando seus cidadãos estão divididos quanto ao significados destes (DWORKIN, 1986, p. 213). A integridade é um fundamento do direito e é o que garante a legitimidade e a operabilidade do direito em sociedade para o autor. $O$ direito como integridade, nesse sentido, interpreta a prática jurídica como uma política em processo, ou como um "romance em cadeia", no qual as decisões da Corte não podem ser negligenciadas numa dimensão histórica, à medida que, também, se refere a uma dimensão prospectiva, apontando para o futuro.

Dessa forma, "o princípio judiciário de integridade instrui os juízes a identificar direitos e deveres legais, até onde for possível, a partir do pressuposto de que foram todos criados por um único autor - a comunidade personificada -, expressando uma concepção coerente de justiça e equidade" (DWORKIN, 1986, p. 271), sendo um direito muito mais interpretativo que o convencionalismo ou o pragmatismo. Nesse sentido, Dworkin cria a figura do juiz "Hércules" como modelo paradigmático de juiz a ser seguido para que se alcance a integridade no campo judicial. O juiz Hércules é aquele que interpreta a Constituição considerando todos os aspectos envolvidos e fazendo o histórico de decisões chegar ao melhor resultado possível (DWORKIN, 1986, p. 456), de modo que "suas conviç̧ões sobre a justiça ou a política sábia se vêem inibidas em seu julgamento interpretativo geral, não apenas pelo texto da lei, mas também por um grande número de considerações sobre a eqüidade e a integridade" (DWORKIN, 1986, p. 457). De acordo com Dworkin (1986),

A Constituição é o fundamento para a criação de outras leis, e por esse motivo a interpretação dada por Hércules ao documento como um todo, bem como a suas cláusulas abstratas, deve ser também fundamental. Deve ajustar-se às disposições mais básicas do poder político da comunidade e ser capaz de justificá-las, o que significa que deve ser uma justificativa extraída dos aspectos mais filosóficos da teoria política. Os juristas são sempre filósofos, pois a doutrina faz parte da análise de cada jurista sobre a natureza do direito, mesmo quando mecânica e de contornos pouco nítidos. Na teoria constitucional, a filosofia é mais próxima da superfície do argumento e, se a teoria for boa, explicita-se nela (DWORKIN, 1986, p. 454).

A missão hercúlea do juiz, nesse contexto, seria livre para se concentra nas questões de princípio, podendo, a partir disso, interpretar disposições, criar direitos e formular ajustes naquilo que acredita ser o certo enquanto questão de princípio (DWORKIN, 1986, p. 454), alcançando, a partir disso, a melhor resposta para determinado caso adjudicado. Para tanto, Dworkin ainda enfatiza a necessidade de desenvolver uma abordagem interpretativa que se pauta numa "leitura moral da Constituição" (1977b), que implica a inserção da moralidade política no próprio âmago do direito constitucional (DWORKIN, 1977b, p. 2), cuja autoridade suprema para compreendê-lo e interpretá-lo é concedida aos juízes, principalmente àqueles da Suprema Corte. A moralidade está integrada nos princípios constitucionais e, por isso, eles devem ser levados em consideração quando for realizada a interpretação que seja condizente com eles - sobretudo com o fundamento do direito que, para Dworkin, se assenta na ideia de equidade, ou igual consideração e respeito ${ }^{25}$. Evidente que há aí uma superação da dicotomia posta entre direito e moral ${ }^{26}$, pondo o direito na dependência dos princípios mo-

\footnotetext{
${ }_{23}$ "O ativismo é uma forma virulenta de pragmatismo jurídico. Um juiz ativista ignoraria o texto da Constituição, a história de sua promulgação, as decisões anteriores da Suprema Corte que buscaram interpretá-la e as duradouras tradições de nossa cultura política. O ativista ignoraria tudo isso para impor a outros poderes do Estado seu próprio ponto de vista sobre o que a justiça exige. O direito como integridade condena o ativismo e qualquer prática de jurisdição constitucional que lhe esteja próxima. Insiste em que os juízes apliquem a Constituição por meio da interpretação, e não por fiat, querendo com isso dizer que suas decisões devem ajustar-se à prática constitucional, e não ignorá-la" (DWORKIN, 1986, p. 451-452).

24 "Temos dois princípios de integridade política: um princípio legislativo, que pede aos legisladores que tentem tornar o conjunto de leis moralmente coerente, e um princípio jurisdicional, que demanda que a lei, tanto quanto possível, seja vista como coerente nesse sentido. Nosso maior interesse é o princípio jurisdicional [...]" (DWORKIN, 1986, p. 213).

${ }^{25}$ Trata-se da noção de justiça que embasa a teoria dworkiniana.

${ }^{26}$ Para Dworkin, a teoria do direito está fundamentada em julgamentos morais e éticos.
} 
rais que são adotados por juízes de determinada época (DWORKIN, 1977b, p. 5) e, a partir disso, o juiz pode transcender a letra da norma jurídica, desde que se funde em argumentos de princípio e respeite a integridade do direito (DWORKIN, 1977b, p. 6).

Levando em consideração esses pressupostos, Dworkin irá construir sua teoria do controle judicial de constitucionalidade. Para ele, os juízes podem anular uma lei ou decisão política tomada pelo Legislativo ou Executivo sem haver qualquer prejuízo ou danos maiores para a democracia, desde que o faça a partir de uma análise comprometida com os argumentos de princípios e a integridade do direito. Desse modo, Dworkin propõe que haverá sempre uma resposta correta mesmo para os chamados "hard cases", aqueles casos em que seja difícil chegar a uma solução jurídica, no qual o papel da interpretação e da argumentação, por parte dos magistrados, assume uma função relevante. Nesses casos difíceis, o juiz pode, com base na teoria da leitura moral da constituição, prever uma solução para o conflito mesmo que não haja previsão no texto constitucional para tanto.

O substancialismo de Dworkin trabalha com a noção de que a Constituição estabelece as condições e os pressupostos fundamentais que devem ser aplicados indiscriminadamente. Assim, "o poder judiciário possui um papel imprescindível no que concerne à jurisdição constitucional, não tendo uma postura passiva diante da sociedade, mas de certo ativismo" (RIBEIRO; CZELUSNIAK, 2012, p. 200)27. Tal ativismo está inscrito na noção de que Dworkin entende que a atuação do Poder Judiciário é um componente fundamental da democracia, devendo a atuação do juiz ser ativa - não no sentido de um ativismo desregrado, como Dworkin bem critica, mas - no sentido de concretizar os valores e princípios fundamentais. A figura de Hércules é a que mais define esse processo.

O Judiciário e, sobretudo, sua instância superior, as Cortes Supremas, funciona na teoria de Dworkin como o "guardião dos valores morais e fundamentais" de uma sociedade. Para ele, não há incompatibilidade desta "atuação" da Corte ante os pressupostos de uma sociedade democrática. Ao contrário, para ele essa atuação do magistrado pode, inclusive, reforçar e fortalecer a democracia. A supremacia judicial é, portanto, um dos pressupostos de sua teoria. Para fundamentar sua concepção de democracia, Dworkin afirma, em primeiro lugar, que a leitura moral da constituição política "não só não é antidemocrática, como também, pelo contrário, é praticamente indispensável para a democracia". Assim, "a democracia não faz questão de que os juízes tenham a última palavra, mas também não faz questão de que não a tenham" (DWORKIN, 1977b, $p$. 9-10), abrindo caminho e espaço para afirmar sua teoria.

Nesse sentido, pode-se afirmar que, diferentemente dos teóricos procedimentalistas, a teoria dworkiana do controle de constitucionalidade parte da dissipação da dicotomia "constitucionalismo vs. democracia" e, consequentemente, se arquiteta com base em três características principais, em esforço de síntese: 1) o direito entendido enquanto uma prática interpretativa; 2) o papel do juiz é de grande relevância na intepretação e aplicação do direito, bem como no controle de constitucionalidade, sendo este o lócus por excelência da democracia, e o judicial review realizado indiscriminadamente e considerado essencialmente democrático; 3 ) uma aproximação do direito com a moral a partir da abertura à teoria dos princípios jurídicos e da negação ao positivismo jurídico.

\section{UMA ANÁLISE CRÍTICA}

A teoria dworkiana passou a ganhar proeminência em grande parte do mundo. De acordo com Conrado Hubner (2008, p. 3), "a maioria das democracias constitucionais contemporâneas apresenta, como filosofia política de base, alguma versão d[a] explicação dworkiniana", o que demonstra uma certa complacência e aderência dos teóricos constitucionais e dos juristas operadores de diferentes sistemas jurídicos para com sua teoria. Mesmo no Brasil, a teoria de Dworkin, desde o início de seus estudos (KARAM, 1993) até hodiernamente $^{28}$, tornou-se hegemônica na literatura jurídica, sobretudo no campo do Direito Constitucional. A classificação das normas como regras e princípios e a consideração - muitas vezes acrítica - de que a argumentação

\footnotetext{
27 Para aprofundamentos, ver Streck (2001).

${ }^{28}$ Talvez o grande expoente seja Luís Roberto Barroso.
} 
e a interpretação passam a ganhar cada vez mais espaço e centralidade dentro do direito brasileiro, que se insere na tradição do civil law, são constatações de que as ressonâncias de sua teoria estão impregnadas no imaginário do pensamento jurídico contemporâneo.

A recepção de sua teoria no Brasil não deixa, entretanto, de ser problemática, e mesmo de surtir efeitos muitas vezes contrários ao que a própria teoria defende e reivindica. O jurista italiano Luigi Ferrajolli relata esta dificuldade em um texto publicado no IX Simpósio Nacional de Direito Constitucional, organizado pela Academia Brasileira de Direito Constitucional, em 2010, intitulado "Constitucionalismo garantista e neoconstitucionalismo", no qual empreende uma análise dos desarranjos da recepção da teoria de Dworkin no Brasil a partir do filtro teórico do garantismo jurídico (FERRAJOLI, 2006). Categorizado no âmbito da celeuma jurídica daquilo que se convencionou chamar de "neoconsittucionalismo"29 é constatável que a teoria de Dworkin foi instrumentalizada para legitimar o agigantamento visceral do poder do Judiciário no Brasil, colocando em xeque aspectos centrais da frágil democracia brasileira.

É nesse sentido que são edificadas as críticas à sua teoria no Brasil. Em efeito, elas se devem, em grande medida, ao fato de que essa teoria, arquitetada em e para outro modelo específico de direito, mostra-se difícil de adequar-se ao sistema constitucional brasileiro, que parte de fundamentos constitucionais diferentes. A dicotomia princípios vs. regras, como aponta Marcelo Neves (2014), não pode ser aplicada de forma indiscriminada no Brasil, na medida em que o sistema constitucional brasileiro reconhece os direitos fundamentais como "regras" jurídicas e não como princípios abstratos. Para Neves (2014), a recepção do debate entre princípios e regras na literatura jurídica brasileira é uma importação acrítica de construções teóricas e dogmáticas, sem o crivo seletivo de uma teoria jurídico-constitucional apropriada. Isso leva, de acordo com Neves (2014), a uma a) banalização dos modelos principiológicos; b) a uma invocação aos princípios - morais e jurídicos como panaceia para solucionar todos os males das nossas práticas jurídicas; e c) a uma retórica principialista responsável pelo afastamento de regras claras e completas para encobrir decisões orientadas à satisfação de interesses particulares (NEVES, 2014, p. 55) - o que representa um grave ameaça ao princípio da segurança jurídica do ordenamento jurídico brasileiro. Trata-se do uso abusivo dos princípios pela jurisdição, além da abertura para a interpretação e argumentação a partir de elementos extrajurídicos ${ }^{30}$ de dispositivos constitucionais ${ }^{31}$.

Da mesma forma, a crença - por vezes messiânica - e com confiança na figura dos juízes e do Judiciário para a solução dos problemas jurídicos - e políticos - relativos aos direitos fundamentais, não demonstra ser uma concepção teórica condizente com o modelo de controle de constitucionalidade brasileiro. Muito embora a atuação do Judiciário - sobretudo das Cortes Superiores - seja de grande relevância para a concretização da Constituição e proteção dos direitos fundamentais, eles não estão - e não devem estar -, no sistema constitucional brasileiro, restritos ao campo de incidência do Poder Judiciário. Muito pelo contrário, a Constituição vincula a atuação do Judiciário, Executivo e Legislativo, além de agentes particulares, da mesma forma que necessitam da "Política" - entendida no sentido arendtiano como "ação pela busca da liberdade" (ARENDT, 2005, 2006) - para sua concretização, seja por meio de políticas públicas, ações do terceiro setor ou mesmo uma decisão judicial. Pode-se ressaltar, portanto, que uma análise da Constituição centrada no âmbito do Poder Judiciário e do controle de constitucionalidade desvirtua as complexas atribuições e responsabilidades jurídicas dos demais Poderes. Além disso, a Constituição ainda garante precipuamente a guarda da Constituição ao STF (artigo 102, caput), não garantindo, portanto, qualquer forma de "supremacia judicial" e nem entende que o Judiciário ou o STF sejam o lócus por excelência da democracia brasileira.

Já os teóricos procedimentalistas são menos trabalhados e analisados na academia brasileira. Desde que seu livro foi publicado, no entanto, Ely passou a receber uma série de críticas por parte de seus intérpretes, sejam eles procedimentalistas ou substancialistas - críticas que também são direcionadas a Habermas. As

\footnotetext{
${ }_{29}$ Para uma compreensão do termo neoconstitucionalismo, seu nascimento e a celeuma teórica que envolve sua aplicação, ver Melo (2013, p. 57-85).

${ }^{30}$ Refiro-me à moral, economia, política, ética, dentre outras possibilidades, que são defendidas pela teoria de Dworkin.

${ }^{31}$ Um exemplo evidente é a tese do "marco temporal", construída pelo Supremo Tribunal Federal no caso Raposa Serra do Sol, em 2009. Para aprofundamentos, ver Burckhart; Melo (2020).
} 
críticas mais comuns direcionadas à sua teoria, sobretudo no que se refere à atuação da corte na proteção de minorias, são sistematizadas por Paul Cox (1981), que questiona "where does process and substance begin?" (p. 641). Esta interrogante evidencia a dificuldade de conceber até onde há procedimento e até onde há substância na teoria de Ely - também na de Habermas -, o que é em efeito difícil de se delimitar claramente, haja vista que esse tema é delineado por uma linha divisória muito tênue.

As críticas dos autores brasileiros seguem na mesma direção, afirmando que é difícil delimitar com precisão a fronteira entre procedimentalismo e substancialismo, considerando-se que todo procedimentalismo possui uma face substancialista que propriamente o sustenta e legitima. A discussão sobre os limites entre o procedimento e a substância é um problema em aberto para os procedimentalistas, haja vista que todo procedimentalismo pressupõe um nível de substancialismo e vice-versa. Nesse sentido, Katya Kozicke e Estefânia Barbosa (2007) mostram que, mesmo o teórico do procedimentalismo democrático, ao advogar em prol de uma jurisdição constitucional tímida e voltada para a garantia dos direitos fundamentais e do processo democrático, "não consegue evitar a possibilidade de que esta jurisdição envolva julgamentos de valores substantivos" (KOZICKI; BARBOSA, 2007, p. 6.763); isso porque, ao defenderem o procedimento democrático na política como pressuposto de legitimação das leis, "os procedimentalistas acabam admitindo algumas pré-condições necessárias a que este procedimento seja o mais adequado, tais como liberdade, igualdade e dignidade dos cidadãos, o que, por sua vez, demonstra condições necessariamente substantivas" (KOZICKI; BARBOSA, 2007, p. 6.763).

Nesta mesma linha de raciocínio ancora-se o entendimento de Maria Eugenia Bunchaft, apontando que tanto perspectivas minimalistas quanto as maximalistas podem ser instrumentos de manutenção do status quo e, portanto, podem estar num grau maior ou menor de acordo com os pressupostos democráticos (BUNCHAFT, 2011, p. 179). Nesse mesmo sentido, Daniel Sarmento e Cláudio Pereira de Souza Neto (2013), ao analisarem a questão da "última palavra" e parâmetros de autocontenção judicial, ressaltam que a dicotomia substancialismo versus procedimentalismo deve ser superada por um lugar intermediário, no qual, de um lado, deve-se reconhecer a importância do papel do Judiciário na garantia da Constituição e dos fundamentos e pressupostos da democracia e, de outro, deve-se valorizar o constitucionalismo que se expressa fora das cortes constitucionais, sobretudo nos parlamentos ${ }^{32}$.

Esta é uma constatação que emerge quando se analisa estritamente o sistema constitucional brasileiro. A Constituição estabelece um amplo rol de possibilidades de julgamento em âmbito de controle de constitucionalidade, como a ação direta de inconstitucionalidade e a ação declaratória de constitucionalidade - esta última é uma inovação brasileira para o constitucionalismo democrático -, ambas previstas no artigo $102, \mathrm{I}$, a, além da arguição de descumprimento de preceito fundamental (artigo 102, § 1). Da mesma forma, a Constituição ainda estabelece a possibilidade de o Supremo Tribunal Federal aprovar súmula de caráter vinculante (artigo 103-A), que, na prática, significa a possibilidade de estabelecer um entendimento que vincula todos os demais órgãos do Poder Judiciário e da Administração Pública. Também é oportuno pontuar que o sistema de processo civil brasileiro coloca que o juiz não pode se eximir de decidir sob alegação de lacuna ou obscuridade do ordenamento jurídico (artigo 140, Código de Processo Civil).

Observa-se, portanto, que não é possível propugnar por uma teoria do judicial review meramente procedimental, isto é, que não leve em conta aspectos também substanciais - que se consubstancia num diálogo com a dimensão material da democracia, implicando a garantia material dos direitos fundamentais - que se encontra no âmago do projeto constitucional de 1988 e da democracia constitucional brasileira. Nesse sentido, Cláudio Pereira de Souza Neto (2007, p. 29-39), ao realizar um estudo sobre a teoria constitucional democrático-deliberativa, destaca que esses autores entendem a igualdade como uma condição da democracia, ou seja, que suas teorias necessitam de um determinado grau de igualdade social para que sejam aplicadas, o que apresenta problemas quando transportada para uma realidade social como a brasileira, marcada por

\footnotetext{
32 "Em nossa opinião, deve-se buscar um lugar intermediário entre estas visões antagônicas. De um lado, deve-se reconhecer o importante papel do Judiciário na garantia da Constituição, especialmente dos direitos fundamentais e dos pressupostos da democracia, sobretudo num contexto como o vivenciado no Brasil de hoje, de profunda crise de representatividade do Poder Legislativo. Mas, do outro, cumpre também valorizar o constitucionalismo que se expressa fora das cortes judiciais, em fóruns como os parlamentos e nas reivindicações da sociedade civil que vêm à tona no espaço público informal" (SARMENTO; SOUZA NETO, 2013, p. 158-159).
} 
uma profunda desigualdade social e econômica pela ineficiência de um Estado Providência, pela prevalência histórica de elites políticas, econômicas e, mais recentemente, religiosas, que se avultam de privilégios, o que marca um claro distanciamento entre o texto e o contexto das disposições constitucionais, e há pouco tempo, pelo processo de desconstituição da República, desconstitucionalização dos direitos e ameaças à ordem democrática ${ }^{33}$.

Dessa forma, um controle de constitucionalidade "discreto", que age somente em prol dos procedimentos democráticos, direitos fundamentais e das minorias, encontra barreiras 1) no próprio modelo de constitucionalidade brasileiro que, ao juntar dois modelos - difuso e concentrado -, propicia que seja menos discreto; 2) na possibilidade também inscrita no modelo brasileiro de uma atuação mais "ativa" e, em alguns casos, "política", dos magistrados no controle de constitucionalidade; 3) e na tônica das promessas inscritas na Constituição Federal de 1988 que, de uma forma ou de outra, acaba por determinar que o Judiciário, quando instado para tanto, venha a participar de sua concretização e/ou efetivação

A incorporação destas teorias, no âmbito da teoria constitucional brasileira, mediante um processo de difusão do modelo jurídico-constitucional estadunidense, sendo resultado de um transplante jurídico teórico (WATSON, 1974; SACCO, 1990; MATTEI, 1994), atua com efeito uniformante na construção teórica constitucional, e deformante do sistema constitucional brasileiro. O uso destas teorias e de autores que provêm de famílias jurídicas distintas - como é o caso da common law, que pouco relaciona-se com a civil law em termos de prática de jurisdição -, caso não seja contextualizado, impõe a deformação do sistema jurídico-constitucional, como é bem avaliada por Marcelo Neves (2014) em um estudo sobre a proliferação dos "princípios constitucionais" e a consequente perda de efetividade do texto constitucional no processo político e jurídico - na jurisdição constitucional.

\section{CONSIDERAÇÕES FINAIS}

Com base nas considerações realizadas neste estudo, pode-se concluir que 1) a dicotomia substancialismo vs. procedimentalismo é inadequada para analisar o modelo de justiça constitucional brasileiro; da mesma forma que, 2) tanto as correntes "procedimentalistas" quanto as correntes "substancialistas", naquilo em que elas prescrevem enquanto proposta teórica e política, são também pouco aderentes, em seu âmago, ao modelo constitucional brasileiro. Isso porque trata-se de uma discussão teórica que corresponde ao modelo constitucional estadunidense, podendo ser, em certo sentido, transposta para os países anglo-saxões da tradição da commom law - com as devidas ressalvas dos respectivos contextos. Essas discussões encontram espaço mais restrito - ou, pelo menos, deveriam encontrar - nos países de civil law, na medida em que a atuação dos magistrados possui especificidades se comparada com aquela dos magistrados da common law - no qual possuem um grau de liberdade maior na resolução dos casos.

A realização de um transplante jurídico teórico neste contexto é, portanto, difícil e precário, sendo, em grande medida, impossível (LEGRAND, 1997). Neste sentido, a hipótese desta pesquisa confirma-se parcialmente, pois entende-se que, se por um lado a dicotomia substancialismo vs. procedimentalismo não é adequada para compreender o sistema constitucional brasileiro, por outro entende-se também que os autores analisados, embora provenham de distintos contextos jurídicos e famílias jurídicas, podem oferecer contribuições teóricas importantes para a compreensão da jurisdição constitucional brasileira, desde que suas teorias sejam efetivamente contextualizadas à realidade constitucional brasileira.

A transposição acrítica do debate jurídico analisado neste trabalho, contudo, é um resultado do 1) desapreço metodológico por parte dos teóricos do direito constitucional, que tendem a conceber que as realidades constitucionais brasileira e estadunidense são similares no campo da justiça constitucional, do mesmo modo que também demonstra 2) o subdesenvolvimento do campo dos estudos comparados do Direito Constitucional e Teoria da Constituição. Em efeito, a academia brasileira pouco se abriu para os estudos comparados no campo jurídico, à medida que ainda são tratados como "perfumaria jurídica" e não com a devida atenção e

${ }^{33}$ Refiro-me, aqui, ao recrudescimento da extrema-direita ultraliberal-conservadora que se mostra paulatinamente crescente no cenário político brasileiro desde a metade do ano de 2013. 
cuidado acadêmicos e metodológicos. Os estudos de comparação jurídica, que não se restringem à comparação de textos jurídicos, são de essencial importância para se compreender os respectivos contextos do nascimento das teorias jurídico-constitucionais e a importação - muitas vezes acrítica - de teorias estrangeiras dos países centrais aos cenários jurídicos da periferia global, do qual o Brasil faz parte.

É importante salientar que tanto as teorias "procedimentalistas" quanto as "substancialistas", representadas pelas obras dos autores analisados, apresentam fragilidades e aberturas que podem servir para sua aplicação de forma contrária àquilo que propugna. Fato notório é a aplicação da teoria de Ronald Dworkin para justificar um "ativismo judicial" desmedido pelo Judiciário brasileiro. Para evitar esses erros que legitimam a perpetuação de "práticas constitucionais autoritárias" além do "senso comum teórico dos juristas" - em referência a Warat -, torna-se importante a contextualização da possibilidade de recepção de teorias alienígenas ao ordenamento jurídico brasileiro.

A análise do modelo de justiça constitucional brasileiro, diante de sua intrínseca complexidade, exige, evidentemente, o diálogo profícuo com as mais diversas teorias do controle de constitucionalidade. 0 "diálogo", no entanto, não pode implicar "importação acrítica". É tarefa e responsabilidade dos juristas brasileiros, diante da pluralidade de teorias sobre a jurisdição constitucional, arquitetar uma teoria condizente com o modelo brasileiro. Neste processo, não há que se descartar todo o conteúdo destas outras teorias estrangeiras, mas, sim, com elas dialogar para que seja possível analisá-las criticamente, com o intuito de averiguar seu grau de adequação ao sistema constitucional brasileiro. É neste âmbito que as teorias sobre o controle judicial de constitucionalidade devem ser concebidas no âmbito da ciência jurídica. É somente levando este pressuposto à sério que se poderá construir teorias constitucionais adequadas à realidade jurídica brasileira.

\section{REFERÊNCIAS}

ACKERMAN, Bruce. The Rise of World Constitutionalism. Virginia Law Review, 83, n. 4, p. 771-797, 1997.

ARANTES, Rogério Bastos. Judiciário e política no Brasil. São Paulo: Fapesp, 1997.

ARENDT, Hannah. O que é política? Trad. Reinaldo Guarany. 6. ed. Rio de Janeiro: Bertrand Brasil, 2006.

ARENDT, Hannah. A condição humana. Trad. Roberto Raposo. 10. ed. Rio de Janeiro: Forense Universitária, 2005.

ATIENZA, Manuel. Constitucionalismo, globalización e derecho. In: CARBONELL, MIGUEL. Neoconstitucionalismo(s). Madrid: Frotta, 2003.

BENTHAM, Jeremy. An introduction to the principles of morals and legislagion. Kitchener : Batoche Books, 2000.

BOBBIO, Norberto; MATTEUCCI, Nicolà; PASQUINO, Gianfranco. Dicionário de política. Brasília: Editora da UnB, 1998.

BRUBACKER, Stanley. Fear of judging: a comementary on Ely's theory of judicial review. The Political Science Review, v. 12, 1982.

BUNCHAFT, Maria Eugenia. Constitucionalismo democrático versus minimalismo judicial. Revista Direito, Estado e Sociedade PUC-Rio, v. 38, 2011.

BURCKHART, Thiago; MELO, Milena Petters. Direitos de povos indígenas no Brasil: o "núcleo essencial de direitos" entre diversidade e integracionismo. Revista Eletrônica do Curso de Direito da UFSM, v. 15, p. 1-28, 2020.

CANOTILHO, José Joaquim Gomes. Direito constitucional. 6. ed. Coimbra: Almedina, 1993.

CORWIN, Edward. Marbury vs. Madinson and the doctrine of judicial review. Michigan Law Review, v. 12, n. 7, 1914.

COX, Paul. John Hart Ely, Democracy and disctrust: a theory of judicial review. Valparaíso University Law Review, v. 15, n. 3, 1981.

DWORKIN, Ronald. Taking rights seriously. Massachussets: Harvard University Press, 1977a.

DWORKIN, Ronald. A matter of principle. Cambridge: Cambridge University Press, 1985.

DWORKIN, Ronald. Law's empire. Cambridge: Cambridge University Press, 1986.

DWORKIN, Ronald. Freedom's law: the moral reading of the American Constitutions. Cambridge: Cambridge University Press, 1977b.

ELY, John Hart. Democracia e desconfiança: uma teoria do controle judicial de constitucionalidade. Tradução Juliana Lemos. São Paulo: Martins Fontes, 2016.

FAVOREU, Louis. La constitucionalización del derecho. Revista de Derecho, v. XIII, 2001.

FERRAJOLI, Luigi. Direito e razão: teoria do garantismo penal. São Paulo: Editora Revista dos Tribunais, 2006. 
FERRAJOLLI, Luigi. Por uma teoria do direito e dos bens fundamentais. Porto Alegre: Livraria do Advogado, 2012 a.

FERRAJOLI, Luigi. Constitucionalismo garantista e neoconstitucionalismo. CONGRESSO NACIONAL DE DIREITO CONSTITUCIONAL, 9., 2012. Anais [...]. Curitiba: Academia Brasileira de Direito Constitucional, 2012b.

FERRO, Ana Luiza Almeida. A teoria procedimentalista de interpretação constitucional de John Hart Ely. Revista do Ministério Público Estadual do Maranhão, v. 1, 2010.

GRANO, Joseph. Ely's theory of judicial review: preserving the significance of political process. Ohio State Law Journal, v. 42 , Issue 1, 1981.

GRIMM, Dieter. Constitutional adjudication and constitutional interpretation: between law and politics. Nujs Law Review, n. 15, 2001.

HABERMAS, Jürgen. Direito e democracia: entre facticidade e validade. Tradução Flávio Siebeneichler. Rio de Janeiro: Tempo Brasileiro, 1997. Vol. I e II.

HABERMAS, Jürgen. Três modelos normativos de democracia. Lua Nova, n. 36, 1995.

HART, Herbert. O conceito de direito. Trad. Ribeiro Mendes. Lisboa: Fundação Calouste Gulbenkian, 2000.

HIRSCHL, Ran. Towards Juristocracy: the origins and consequences of the new constitutionalism. Cambridge: Harvard University Press, 2007.

HUBNER, Conrado. Direitos fundamentais, separação dos poderes e deliberação. 2008. Tese (Doutorado em Ciência Política) Universidade de São Paulo, São Paulo, 2008.

HUNTER, Tina. Interpretative theories: Dworkin, Sunstein e Ely. Bond Law Review, v. 17, Issue 2, 2005.

KARAM, Vera. A filosofia jurídica de Ronald Dworkin com possibilidade de um discurso instituinte de direitos. 1993. Dissertação (Mestrado em Direito) - Universidade Federal de Santa Catarina, 1993.

KELSEN, Hans. Jurisdição constitucional. São Paulo: Martins Fontes, 2003.

KOZICKI, Katya; BARBOSA, Estefânia Maria de Queiroz. Democracia procedimental e jurisdição constitucional. In: CONGRESSO NACIONAL DE CONPEDI, 16., 2007. Florianópolis. Anais [...]. Florianópolis: Fundação Boiteux, 2007.

LEGRAND, Pierre. The Impossibility of Legal Transplants. Maastricht Journal of European and Comparative Law, 1997.

MATTEI, Ugo. Efficiency in legal transplants: an essay in comparative law and economic. Review of Law and Economics, 1994.

MEDEIROS, Orionte Dantas de. O controle de constitucionalidade na Constituição brasileira de 1988: do modelo híbrido à tentativa de alteração para um sistema misto complexo. Revista de Informação Legislativa, a. 50, n. 200, out./dez. 2013.

MELO, Milena Petters. As recentes evoluções do constitucionalismo na América Latina: neoconstitucionalismo? In: WOLKMER, Antonio Carlos; MELO, Milena Petters (org.). Constitucionalismo latino-americano. Tendências contemporâneas. 1. ed. Curitiba: Juruá, 2013.

MIGUEL, Luis Felipe. Democracia e representação: territórios em disputa. São Paulo: Editora Unesp, 2014.

NEVES, Marcelo. Entre Hidra e Hércules: princípios e regras constitucionais como diferença paradoxal do Sistema Jurídico. São Paulo: Martins Fontes, 2014.

NINO, Carlos Santiago. La constitución de la democracia deliberativa. Barcelona: Gladisa, 1997.

ONIDA, Valerio. La Costituzioni ieri e oggi. Bologna: II Mulino, 2008.

POLI, José Vinícius. Controle de constitucionalidade: das teorias da última palavra à teoria do diálogo. 2012. Dissertação (Mestrado) - Programa de Pós-Graduação em Direito. Universidade de São Paulo, 2012.

RADKE, Rafael; TEIXEIRA, Anderson. Habermas e a tentativa procedimental de superação da discricionariedade judicial. Revista Brasileira de Estudos Políticos, Belo Horizonte, n. 155, jul./dez. 2017.

RIBEIRO, Marcia Carla Pereira; CZELUSNIAK, Vivian Amaro. Constitucionalismo e democracia nas análises procedimentalistas e substancialistas. Sequência, Florianópolis, n. 65, 2012.

SACCO, Rodolfo. La circulation des modèles juridiques. Rapports géneraux. CONGRÈS INTERNATIONAL DE DROIT COMPARE, 13., 1990. Montreal, 1990.

SANTOS, Boaventura de Sousa; AVRITZER, Leonardo. Para ampliar o cânone democrático. In: SANTOS, Boaventura de Sousa (org.). Democratizar a democracia: os caminhos da democracia participativa. Rio de Janeiro: Civilização Brasileira, 2002.

SARMENTO, Daniel; SOUZA NETO, Cláudio Pereira de. Notas sobre jurisdição constitucional e democracia: a questão da "última palavra" e alguns parâmetros de autocontenção judicial. Revista Quaestio luris, v. 6, 2013.

SCHMITT, Carl. O guardião da Constituição. Belo Horizonte: Del Rey, 2007.

SOUZA NETO, Cláudio Pereira de. Teoria da Constituição, democracia e igualdade. In: SOUZA NETO, Cláudio Pereira de et al. Teoria da Constituição: estudos sobre o lugar da política no Direito Constitucional. Rio de Janeiro: Lumen Juris, 2007. 


\section{Direito屏 \\ Debate}

JURISDIÇÃO CONSTITUCIONAL NO BRASIL: UMA ANÁLISE CRÍTICA DA DICOTOMIA SUBSTANCIALISMO VS. PROCEDIMENTALISMO Thiago Rafael Burckhart

STRECK, Lenio Luiz. Hermenêutica jurídica e $(m)$ crise: uma exploração hermenêutica da construção do direito. 3. ed. rev. Porto Alegre: Livraria do Advogado, 2001.

TUSHNET, Mark. The inevitable internationalization of constitutional law. Virginia Journal of International Law, v. 49:4, 2009. WATSON Alan. Legal Transplants: An Approach to Comparative Law, 1974.

ZAGREBELSKY, Gustavo. El derecho dúctil: ley, derechos, justicia. Madrid: Trotta, 2003. 